Say goodbye to the fries: Graduate careers in media, cultural and communication studies

Stuart Cunningham and Ruth Bridgstock

Stuart Cunningham is Distinguished Professor of Media and Communications and Director of the ARC Centre of Excellence for Creative Industries and Innovation, Queensland University of Technology

Dr Ruth Bridgstock is Vice-Chancellor's Research Fellow, ARC Centre of Excellence for Creative Industries and Innovation, Queensland University of Technology. 


\title{
Say goodbye to the fries: Graduate careers in media, cultural and communication studies
}

\begin{abstract}
This article addresses the paucity of systematic data on graduate careers in the arts and humanities in the broader context of enduring public and policy debates about the benefits of education to society, the relation between public and private good that is derivable from education, and the specific disciplinary angle that can be brought to bear on these questions from media, cultural and communication studies. We report findings from a survey of ten years of graduates from Queensland University of Technology’s courses in media, cultural and communication studies which indicate very high employment levels and generally positive accounts of the relevance of courses to working life. A major insight that can be drawn from the research is that media, cultural and communication studies deliver capabilities, skills and orientations which are themselves strongly aligned with the kinds of transferable generic attributes which facilitate transition into the workplace.
\end{abstract}


There is a radical paucity of systematic data on graduate careers in the arts and humanities in general, and more specifically, for our purposes and for readers of this journal, in media, cultural and communication studies. Nature, or in this case, urban myth and rumour, abhors a vacuum, and so the old jokes about arts and humanities students graduating to McJobs - 'do you want fries with that?' - are hard to put to rest. This article addresses this lack in the broader context of enduring public and policy debates about the benefits of education to society, the relation between public and private good that is derivable from education, and the specific disciplinary angle that can be brought to bear on these questions from media, cultural and communication studies.

At the most general level, the public policy debate is framed by a very broad argument about the benefits of education to society. We live in a period which has internalised the insights of endogenous growth theory which holds that human capital plays a more significant role in economic growth than classic theories of finance capital, land and labour. In endogenous growth theory, as developed by Kenneth Arrow, Paul Romer (1994) and others, 'investment in human capital, innovation, knowledge and education are significant contributors to economic growth... growth in these models was due to indefinite investment in human capital which has spillover effects on the economy and reduces the diminishing return to capital accumulation’ (Wikipedia: ‘Endogenous growth theory’).

While remaining contestable, there is now a body of economic research which suggests that the rate of return on education investment can run as high as $15 \%$ and that the average Australian graduate earns \$1.5 million more than a school leaver over the course of a working life - \$500,000 of which goes straight to government in tax (Withers 2011). These strongly embedded accounts of the productivity of educational investment have been broadened to include, in summary, that education is an investment in human capital which benefits society 
through higher productivity and wages (higher private after-tax income and higher tax receipts). There are also spill-over non-financial society benefits, such as better health, child care, and related social outcomes (which include private benefits and savings in government outlays) (Freebairn 2011), as well as a society more able to cope with change and embrace innovation - its 'absorptive capacity'. This is the basis for very significantly increasing preparedness to invest in education at the household level, and a generally positive predilection towards education on the part of most contemporary governments, summed up by Tony Blair in his early days as UK Prime Minister as: the three highest priorities of his government were to be 'education, education, education'.

At this level of generality, differences amongst discipline clusters (for example, humanities and social sciences as distinct from physical and biological sciences) matter little. However, as soon as we descend from these Olympian heights, the differentiations often tell against the humanities, arts and social sciences. No one contests the prudence of mixing arts, humanities and science during the compulsory years of education provision, and the controversies over funding for primary and secondary education rarely are ones fought over discipline differentiation. But they begin to be felt across the board in higher education.

A key differentiator is that between 'public good' and 'private good'. There is fine-grained differentiation between public and private good through much of higher education funding principles and mechanics. Research degrees are considered to retain a significant element of public good, whereas postgraduate coursework is considered to be predominantly the acquisition of a private good; thus the difference between Commonwealth-supported and fee paying courses. Differentiation between public and private good is built also into the Relative Funding Formula governing the setting of differential HECS at the undergraduate level. The 
index used is early career salary levels earned as a result of graduating from different courses together with relative costs of course provision.

Census data on male bachelor degree graduates and their median weekly income in 2006 shows systematically lower income results for arts graduates over the entire working lifespan (Australian Bureau of Statistics, 2007), as shown in Figure 1. But this hasn't stopped demand for arts and humanities appreciating recently, and continuing to remain a significant proportion of total higher education load (DEEWR, 2011), as depicted in Figure 2.

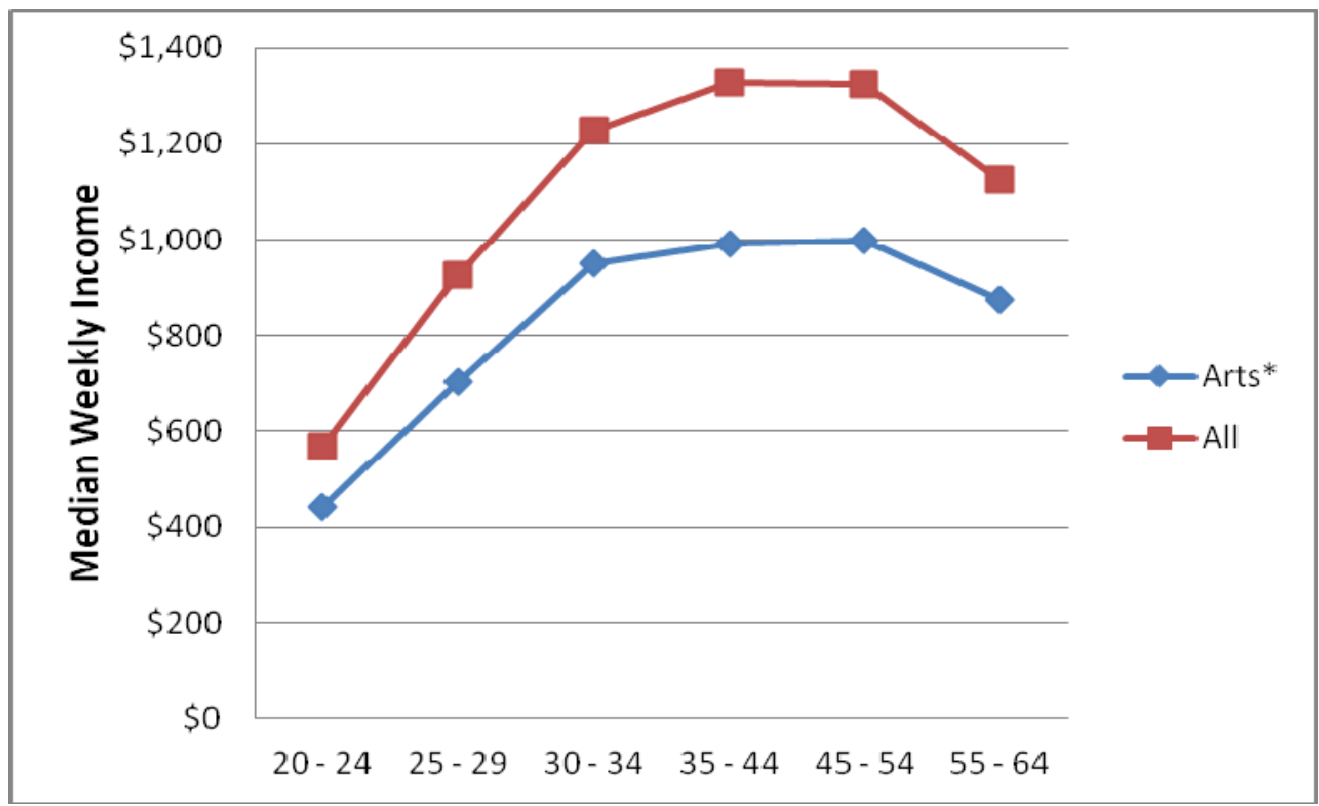

*'Arts' denotes Political Science and Policy Studies, Studies in Human Society, Language and Literature, Philosophy and Religious Studies, and Arts. Income figures are mid-point of Census categories.

Figure 1. Male bachelor degree graduates median weekly income by age group, 2006. We thank Andrew Norton (2011) for the original rendering of data in Figure 1 and 2 in graphic form. 


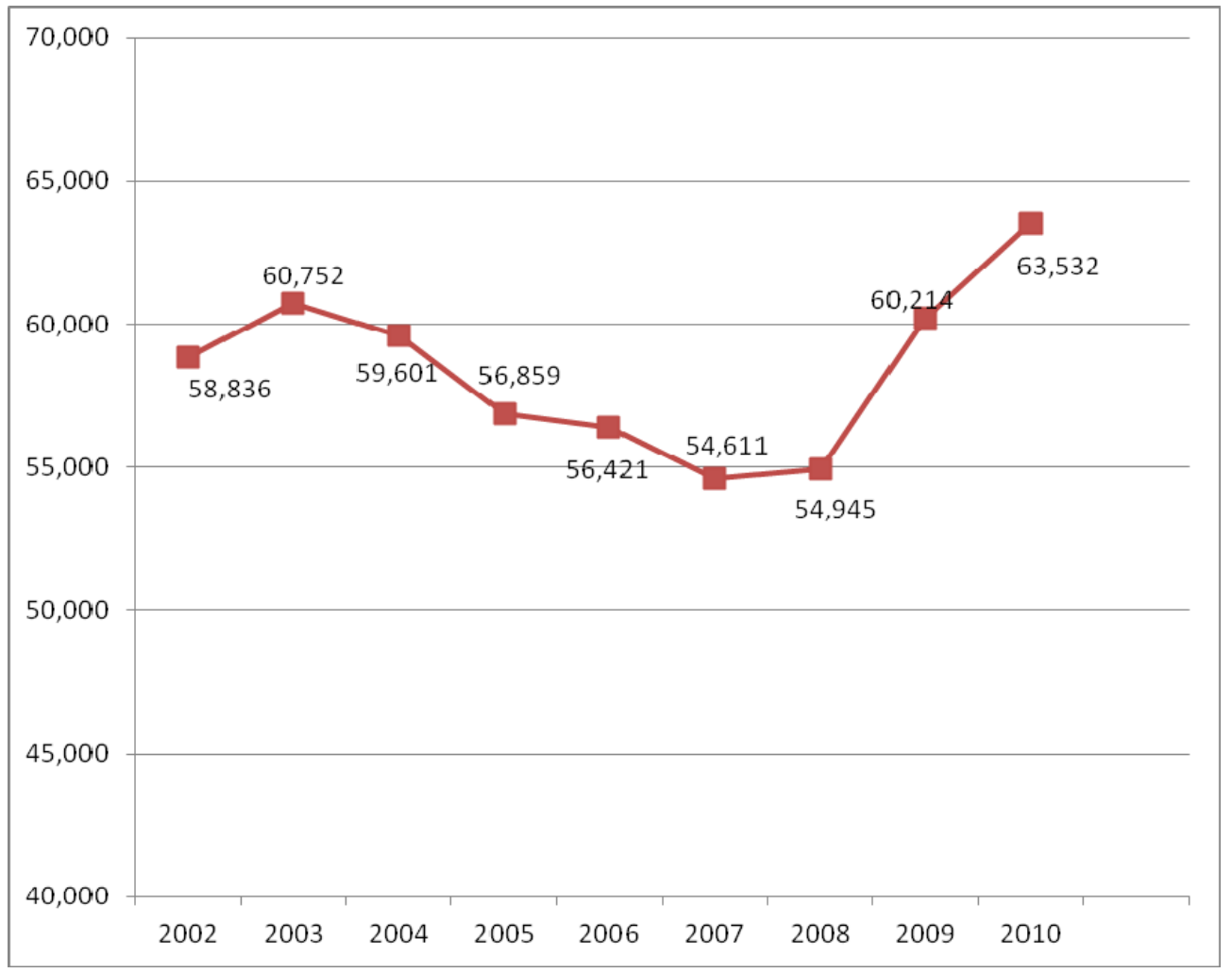

Figure 2. Applications for Australian society and culture/ creative arts undergraduate courses by year, 2001-2010.

These kinds of data can be used as evidence of a regretful market failure. There is enduring demand for disciplines which don't deliver an efficient private good return on investment in education (less productivity, lower income and thereby lower taxation), while the self-evident public good that science, engineering and maths deliver to our knowledge and industry base is in crisis because of preferences for 'dumbed-down' curricula and soft choices. Such arguments contribute to decisions like that in the fiscally-challenged UK to withdraw public subsidy for course costs top-ups for much of humanities, arts and social sciences.

It doesn't help either when argumentation in favour of arts and humanities often begins with existential dread over the non-translation of effort into income, and then proceeds to comfort itself with the assurance that the benefits are always uncaptureable with standard measures of 
private good. This was in evidence in the public debate in a piece in The Australian Higher Education which lamented that

The fact is that students are increasingly perceiving, very understandably, ... That in choosing an area of the humanities they are also choosing, to an even greater extent than would have been the case in the past, insecurity, penury, unemployability and a low status within society, if not actual alienation within it. (Hollier 2011: 31)

And the author quotes Macquarie University Vice-Chancellor Stephen Schwartz to the effect that

Not once have I encountered a retiree [at university graduation ceremonies] whose return to university was driven by a passion for accounting or marketing or business administration. When working life wanes and it comes time to feed the soul, only the humanities provide the required nutrition.

There is little point in disagreeing with the intent of any of these sentiments in and of themselves - we have to confront head-on the perception that arts and humanities education not only does not deliver sufficient private good as measured by the raw but powerful income indicator, but also, as well, they may fail to deliver the less tangible cultural capital and human capital benefits which the traditional defences of these fields have routinely regarded as of deeper civilisational importance. And we certainly have to come up with something more than that the humanities prepare us for retirement and the afterlife!

The task, then, is to outline an approach to the public good that may be derived from the arts and humanities, while also painting a more accurate picture of the capturing of private good by studying more systematically the career outcomes of arts and humanities graduates. It may be that a deeper empirics of career outcome, together with a more sophisticated account of 
public good, may contribute to understanding distinctive ways in which arts and humanities' (or at least the media, cultural and communication studies disciplines which are the primary focus of this research) generation of private good also contributes to the public good - they are not mutually exclusive.

We could initiate this task by noting that the dominant proportion of higher education load is carried in humanities, arts and social sciences. We have already noted the argument that this may represent a ‘dumbing down’ of the system: occasioned by the major and rapid opening up of access to higher education which has proceeded over the past twenty and more years, this takes the form of a crisis of engagement with more challenging curricula in science and mathematics which carry prime public good as they act as the platforms for the knowledgebased society. Against this, it can be argued that the relative popularity of humanities, arts and social sciences disciplines is rational choice decision-making in the light of the broad economic structure of post-industrial societies, like Australia's, with the services sector generating more than $80 \%$ of the nation's GNP and absorbing more than $80 \%$ of the workforce. As we have seen, arts and humanities graduates, together with social sciences graduates, earn less than other classes of graduate. This is consistent with broad service sector outcomes. A significant proportion of such graduates are in public sector employment, where pay rates are lower but public good outcomes are, in principle, higher. In the private sector, many graduates from media, cultural and communication studies are in the business of public sphere communication, using attitudes and aptitudes derived, with self-reported high correlation in the research findings we present here, from the courses they have taken. We will return to these suggestions of distinctive relationships between private and public good in media, cultural and communication studies. First, though, we need to turn to the empirical challenge. 
The first thing we must confront in knowing more about graduates' career outcomes is the parlous state of available data. There is almost no longer-term career tracking research of graduate outcomes in Australia. The Graduate Destination Survey, conducted far too soon after graduation, is worse than having nothing at all, as it tiresomely reiterates the fact that graduates from the arts and humanities take longer to find their feet than those whose career paths are much more tightly aligned to the established salaried professions. The extant statistical data from the Graduate Destinations: National Research Student Survey (Graduate Careers Council of Australia, 2010) has significant statistical reliability issues, and aggregate arts and humanities outcomes at a level of generality unsuitable for specific disciplinary investigation, such as we attempt in this paper.

A study supported by the Deans of Arts, Social Sciences and Humanities (Gannaway and Trent, 2008) and the Australian Learning and Teaching Council into the 'Nature and Roles of Arts Degrees in Contemporary Society: A national scoping project of Arts programs across Australia' focuses on the complexity, diversity and popularity of the general arts degree, staffing, curriculum, technology and content issues. However, the final scoping study report (Gannaway \& Trent, 2008) does not contain information about graduate outcomes or graduate employability.

In 2009, the Australian Council of Educational research published a 'Graduate Pathways Survey Report (Coates \& Edwards, 2009), which documented the five-year career outcomes of 9,000 graduates from Australian degree programs in 2002. This study included 'society and culture' graduates, broadly defined, and surveyed 2,300 graduates from social sciences and humanities courses in a single category. The study documents that at five years after course completion, $68 \%$ society and culture graduates had full-time work (vs all graduates 
75\%), gave course satisfaction ratings corresponding to 'good', and on average also gave 'good' course relevance ratings.

The objectives of a Go8 PhD study (Western et al 2007) were to examine the quality of PhD training of recent PhD graduates from the Go8 universities, and to identify those elements of PhD programs that were associated with successful employment outcomes in diverse labour markets. The study involved a survey of the employment trajectories and experiences of a cohort of recent $\mathrm{PhD}$ graduates across all disciplines from the Go8 universities, along with retrospective evaluations of their doctoral training, and assessments of the skills and knowledge requirements of their current jobs.

One aspect of the survey assessed perceived gaps in skills needs as a result of some years of workplace experience. Significant gaps between training received as a $\mathrm{PhD}$ student and workplace need were reported in: oral communication, teamwork, project management, leadership, assertiveness, development of professional practice, skills for grant writing, and financial management (Max King, Informa conference, 3-4 August 2011). The Go8 PhD study focuses solely on research student graduate outcomes and is not discipline- or fieldspecific.

Other relevant research is the body of work produced through the ARC Centre of Excellence for Creative Industries and Innovation (CCi) on measuring the 'creative workforce' (see, for a summary, Cunningham 2011). This research into the so-called creative workforce has shown that, properly mapped, the creative workforce is growing at a significantly faster rate than the general economy; that, apart from music and the visual and performing arts, the creative workforce is earning wages and salaries above the national average; and that more of this workforce is found 'embedded' in the general economy than is found as 'specialists' inside the creative industries themselves. This research tracks occupations which we would all 
recognise as belonging to media, cultural and communication studies, such as those in journalism, public relations and other related communications occupations. Thus, there is some overlap in terms of workforce category with the research findings presented here. Methodologically, however, there can be no direct correlation, as the creative workforce research treats population-level census data and takes no direct account of qualification data, whereas the field research reported here is a bottom-up survey that tracks directly from qualification to career outcome.

The study reported here had three specific research objectives: (1) to document the early career destinations and career paths of graduates from media, cultural and communication studies (MCCS) courses; (2) to investigate the degree of congruence between skills developed during media, cultural and communication studies courses and skills required in the workforce; and (3) to explore the kinds of value that MCCS graduates add through their work.

\section{Methodology}

\section{Sampling}

The sampling frame contained 1,820 contact records from the Queensland University of Technology student alumni database, representing all graduates from undergraduate and postgraduate media, cultural and communication studies-related courses from 2001-2010. Graduates from a total of twenty-eight courses were included in the sample. Fifteen of the courses were 'vocational' courses with clear professional pathways such as journalism, and thirteen were 'non-vocational' courses, such as mass communication and media/communications. The top 10 most common vocational and non-vocational courses included in the study are presented in table 1. 
Table 1. Top 10 most common vocational and non-vocational courses included in the study by number of participants.

\begin{tabular}{ll}
\hline 'Vocational' courses & 'Non-vocational' courses \\
\hline Bachelor of Journalism $n=80$ & Bachelor of Mass Communication \\
Bachelor of Creative Industries & $\mathrm{n}=54$ \\
(Journalism) $n=57$ & Graduate Certificate of Creative \\
Graduate Certificate of Journalism $n=13$ & Bachelor of Creative Industries \\
& $\begin{array}{l}\text { (Media and Communications) } n=10 \\
\text { Braduate Diploma of Journalism } n=8\end{array}$ \\
& $\begin{array}{l}\text { Bachelor of Creative Industries } \\
\text { (Interdisciplinary) Hons } n=9\end{array}$ \\
Master of Journalism $n=5$ & Bachelor of Creative Industries \\
& (Interdisciplinary) $n=7$ \\
\hline
\end{tabular}

In addition, 87 of the 403 study participants graduated from dual/double degrees - most commonly B Journalism/B Business ( $\mathrm{n}=25$ ) and BCI (Media Communications)/B Business $(n=27)$, but also a small number of double degrees with Law.

\section{Data collection}

The survey was conducted by telephone over a one week period in September, 2011. A team of research assistant interviewers made up to three contact attempts (home phone, mobile phone, work phone) for each alumni database contact record. If contact was successfully made and permission granted to conduct the interview, interviewers read out survey questions and entered participant answers verbatim in to an online form. 
The survey instrument asked graduates to document details of their last six jobs, including job role name, company, basis for employment, region, length of tenure, whether the job was a concurrent job or overlapped with another job; whether the job was a government job or private sector; and whether the job was 'embedded', 'specialist', or 'support' (as per the previous research by CCi on measuring the creative workforce). The instrument also contained questions about unemployment and time out of the workforce, any study at certificate level or higher undertaken since graduation; graduate perceptions of the degree of course relevance andfrom skills used; and any perceived gaps in course provision.

Responses to open ended questions relating to job titles and skills were coded post hoc. Job titles were coded using standard ANZCO codes (Australian Bureau of Statistics, 2006), and special codebooks were developed for the skills questions.

\section{Response rates}

Of the original sample of $1,820,36 \%(n=655)$ of the supplied contact numbers were either disconnected, or the participant was no longer contactable at that number. Of the 1,165 live phone numbers supplied, 403 surveys were conducted, 71 declined to participate, and 569 were not able to be contacted (answering machine; numbers rang out). A further 122 were overseas. The overall response rate, calculated as the percentage of potentially contactable participants who were actually surveyed, was a statistically robust 34.59\%.

The survey captured predominantly recent graduates (the modal graduation year was 2008, with 72 graduates). But it also had a proportion of 'deeper' graduate outcomes going back to 2001, with 201 graduates from the year 2007 or earlier, enabling comparisons between recent graduates and those with more established careers. Three quarters of the participants (74.7\%) were female, and the median age was 26 . 


\section{Results}

Most recent job

The information gathered about work types indicates that in general, graduates maintained an ongoing career commitment to communication and cultural studies, and that there are fulltime, career-level positions available to MCCS graduates. Four in five (80\%) of the participants were employed full-time; 70\% were employed in jobs requiring a degree; and $62 \%$ were employed in jobs they regarded as directly related to their MCCS courses. There was no difference between 'vocational' and 'non-vocational' course graduates in terms of course-job relatedness $\left(\chi^{2}(1)=.51, \mathrm{p}>.05\right)$.

While the majority of participants reported that they held a job which was related to their MCCS degree, their specific job destinations were diverse. Participants held a total of 110 different job titles. For both double and single degree graduates, the most common jobs were in marketing (10\%), public relations (11\%), and journalism (13\%) (see Table 2). As expected, single degree graduates were more likely than double degree graduates to hold arts \& media positions, and double degree graduates were more likely to hold Business, HR and marketing roles.

Table 2. Most common specific recent job roles and broad fields of work (N=403).

\section{Specific job roles - ANZCO 6 digit codes}

Public Relations Manager

Marketing Specialist

Program or Project Administrator

Television journalist

Print journalist

\section{$7.9 \%$}

$7.4 \%$

$5.6 \%$

$5.1 \%$

$4.9 \%$ 


\section{Broad fields of work - ANZCO 2 digit codes}

\begin{tabular}{lc}
\hline Arts and Media Professionals & $23.8 \%$ \\
Business, Human Resource and Marketing Professionals & $20.5 \%$ \\
Specialist Managers & $13.7 \%$ \\
Office Managers and Program Administrators & $6.0 \%$ \\
Education Professionals & $5.7 \%$ \\
\hline
\end{tabular}

One quarter (24.9\%) of the participants were engaged in 'embedded' jobs - that is, employed in media, cultural and communication studies jobs outside the media, cultural and communication studies 'sector', and 38.7\% were 'specialists', that is, employed in MCCS jobs within the MCCS sector. Just 3\% were in MCCS 'support' roles. Non-vocational graduates were much more likely to be embedded, and much less likely to be specialist, than vocational graduates $\left(\chi^{2}(1)=29.05, p<.0001\right)$, with 59.2\% embeddedness among non-vocational graduates, and $25.3 \%$ embeddedness among vocational graduates. Although comparative data on graduates of other disciplines is not available, a seemingly high proportion of the cohort nearly one-third (29.5\%) - were employed in Government positions.

There was a fairly low percentage unemployment rate among the study participants although $24 \%$ had been unemployed at some point since graduation, the average length of 
time unemployed was only 2 months. Only $4 \%$ of the cohort had been unemployed more than once since graduation.

\section{Career trajectories}

For many in the study cohort, the first year after course completion had involved a period of transition to the workforce involving multiple job-holding, higher levels of casual work, voluntary work, work not related to the MCCS course, and non-degree level work. This pattern resolved in years 1-2 after course completion, and we see a consistent pattern of fulltime, MCCS-related work requiring a degree, as shown in Table 3.

Table 3. Graduate trajectories MCCS graduates 0-4 years after course completion

\begin{tabular}{|c|c|c|c|c|}
\hline & $\begin{array}{l}>=1 \text { year } \\
\text { out }\end{array}$ & $\begin{array}{l}\text { 1-2 years } \\
\text { out }\end{array}$ & $\begin{array}{l}\text { 2-3 years } \\
\text { out }\end{array}$ & $\begin{array}{l}\text { 3-4 years } \\
\text { out }\end{array}$ \\
\hline \% multiple & & & & \\
\hline $\begin{array}{l}\text { concurrent or } \\
\text { overlapping jobs }\end{array}$ & $23.0 \%$ & $16.8 \%$ & $18.7 \%$ & $17.7 \%$ \\
\hline$\%$ casual work & $19.7 \%$ & $9.6 \%$ & $4.1 \%$ & $7.3 \%$ \\
\hline$\%$ full-time work & $61.8 \%$ & $76.8 \%$ & $80.3 \%$ & $80.5 \%$ \\
\hline $\begin{array}{l}\text { \% voluntary/unpaid } \\
\text { work }\end{array}$ & $5.9 \%$ & $.8 \%$ & $1.6 \%$ & $1.2 \%$ \\
\hline $\begin{array}{l}\text { \% work related to } \\
\text { MCCS fields }\end{array}$ & $55.1 \%$ & $69.6 \%$ & $65.3 \%$ & $70.7 \%$ \\
\hline $\begin{array}{l}\text { \% work requiring a } \\
\text { degree }\end{array}$ & $55.3 \%$ & $68.8 \%$ & $67.2 \%$ & $67.1 \%$ \\
\hline \% specialist & $35.5 \%$ & $36.8 \%$ & $41.0 \%$ & $49.4 \%$ \\
\hline
\end{tabular}




$\begin{array}{lcccc}\text { \% embedded } & \mathbf{1 9 . 7 \%} & 29.6 \% & 25.4 \% & 23.5 \% \\ \text { \% support } & \mathbf{9 . 2 \%} & 6.4 \% & 3.3 \% & 4.9 \% \\ \text { \% non-trident } & \mathbf{3 5 . 5 \%} & 27.2 \% & 30.3 \% & 22.2 \%\end{array}$

About one quarter of the study cohort (26\%) had engaged in further formal study at certificate level or higher. A significant proportion of those who did engage in further study stayed within the discipline cluster (29\%), and continued to more advanced levels of study, which suggests strong satisfaction with, and commitment to, MCCS career trajectories. A further $18 \%$ of those who went on to further study engaged in courses in Business/Management fields.

\section{Course relevance and skills used}

Participants were asked to rate on a 1-5 Likert scale (ranging from 'strongly disagree' to ‘strongly agree’) the extent to which they agreed that their MCCS studies at QUT had been relevant to their careers so far. They were also asked to rate the extent to which they used the skills, abilities and knowledge they developed during their QUT MCCS related course in their most recent job (105 scale ranging from 'not at all’ to 'a great extent').

On average, participants believed that their QUT MCCS studies were moderately related to their careers (mean=3.5, SD=1.27), and that they used skills they developed during their courses to a moderate extent (mean=3.30, $\mathrm{SD}=1.27$ ). Vocational course graduates assigned somewhat higher course relevance ratings, on average, than non-vocational course graduates (mean=3.7, $\mathrm{SD}=1.27$ vs mean=3.3, $\mathrm{SD}=1.23, \mathrm{U}=15307.500, \mathrm{p}<.0001$ ). 
Participants most commonly emphasised generic skills when talking about skills developed during their courses and now used at work - including professional written communication, professional verbal communication, and visual/digital communication, along with time, team and project management (together accounting for 65\% of all skills reported). Disciplinary skills (particularly journalism disciplinary skills) accounted for another $21 \%$ of reported relevant skills. The most commonly mentioned relevant skills are presented in Table 4.

Table 4. Most commonly mentioned skills developed during MCCS courses relevant to work

\begin{tabular}{ll}
\hline Skill category & \% of reported skills \\
\hline Written communication & $33.6 \%$ \\
Disciplinary knowledge and skills & $21.4 \%$ \\
Verbal communication, interpersonal skills & $15.3 \%$ \\
Visual communication, digital & $8.8 \%$ \\
communication skills & \\
Time, team and project management skills & $6.6 \%$ \\
\hline
\end{tabular}

A total of $83 \%$ of the participants said that graduates from MCCS courses had special skills which added particular value to the workplace. These special skills included: written communication; the ability to apply theoretical knowledge practically; critical and analytical thinking; media-related disciplinary skills; and verbal communication skills, as shown in Table 5.

Table 5. Most commonly reported special value-adding skills possessed by MCCS graduates

Skill category $\quad \%$ of reported skills




\begin{tabular}{lc}
\hline Disciplinary skills and knowledge - & $25.4 \%$ \\
particularly media knowledge & \\
Written communication & $25.4 \%$ \\
Critical thinking, problem solving & $12.2 \%$ \\
Verbal communication and interpersonal & $11.6 \%$ \\
skills & \\
Time, team and project management skills & $7.1 \%$
\end{tabular}

\section{Course skill gaps}

When asked to list required skills which weren’t covered in their QUT MCCS courses, participants tended to emphasise specific industry- and practice- based skills arising from internships and work experience (41\% of comments), and indicated that more industry exposure would have been helpful during their degrees. They also wanted courses to include digital skills development relating to the specific software packages used most commonly in industry (17.8\% of comments), employability / entrepreneurship skills (15.4\% of comments), and social networking / social media (8.2\% of comments).

There were differences in reported course skill gaps by recent ( $<1$ year) and less recent $(>1$ yr) graduates. Recent graduates ( $<1$ year) were significantly more likely than less recent graduates to report course gaps in terms of industry-based digital and software skills (37.0\% vs $14.4 \%$ of comments). Recent graduates were less likely to report course gaps in practicebased industry knowledge and experience (19.6\% vs 45.0\%) of comments) and social networking and social media (0\% vs $9.7 \%$ of comments).

\section{Limitations of the study}


There are a number of methodological limitations which must be acknowledged and addressed when interpreting the findings of this study. First, while the sample was relatively large and the survey response rate respectable (Dillman et al., 2009), the sampling frame only included contact records for MCCS graduates from one university, and therefore the generalisability of the results to Australian MCCS graduates more broadly is somewhat limited. This limitation might be ameliorated if the study were to be replicated in other Australian universities offering similar courses. Second, the study took a retrospective approach to surveying. Participants were asked to recall their employment and study experiences as far back as a decade prior to the survey. Some inaccuracies in responses can therefore be expected, particularly among participants who graduated several years ago. Third, the survey was necessarily not anonymous, and was conducted by interviewers from QUT. Responses could have suffered from bias due to social desirability and other measurement effects. The potential effect of this third shortcoming was minimised by the inclusion of interview scripting which separated the research project from QUT Creative Industries Faculty, and indicated that only aggregated findings would be shared.

\section{Implications}

Despite the general dearth of studies of career outcomes from the specific media, cultural and communication fields, some recent work is generative of fruitful lines of inquiry. The Cultural Studies Review (2011) special issue on 'Disciplining Innovations’ is dedicated to addressing, in the words of the issue editors, 'The challenge ... to develop a pedagogy that preserves the rigour of critical cultural literacies while presenting a coherent understanding of teaching as a positive social function' (6). Interestingly, several of the themed articles report survey results, albeit small-scale, exclusively qualitative, and generally not focused on graduate outcomes. Nick Mansfield (2011), in ‘Teaching Illiteracy’, draws on data which 
show the extent of failure to authentically internationalise curricula. Rebecca Rey and Golnar Nabizadeh (2011), in 'Going Places: Praxis and Pedagogy in Australian Cultural Studies', report on a survey of cultural studies students at the University of Western Australia which focuses on their desire for more practice in their studies.

The most relevant in the light of our graduate outcomes study is Nicole Matthews'(2011) 'Transition or Translation?: Thinking Through Media and Cultural Studies Students' Experiences after Graduation’. Matthews works with the concept of 'instrumental progressivism', seeking to disengage it from its authors, Kevin Robins and Frank Webster, for whom, she says, it is 'a symptom of a wounded and collapsing educational system (29)'. Instrumental progressivism is a driving force in contemporary university educational policy which yokes together two supposedly contradictory ideals: humanist and progressive educational ideas about student empowerment and lifelong learning and the idea that higher education should serve the economy (29). This latter is essentially a 'template' discourse usually pilloried as neoliberal - the realisation of full human (capital) potential and its alignment with workforce, economy and innovation. (It was played out, for example, as a fundamental argument for the necessity to embed multiculturalism into the Australian polity - without such embedding, whole swathes of human capital would be underutilised and the resources of community language competence and links especially to Asia would be suboptimal (see, for example, Cope and Kalantzis 2003).

Matthews works with the concept in a complex dialogue: annoyed with Robins and Webster's sneering putdowns of newer universities' vocationalism as inimical to criticality, painfully aware of the often yawning gap that opens up for fresh graduates between the knowledge gained in university and what they can ‘do’ with their degree, and the ethical 
obligations on educators take this seriously - that gives rise to her replacement of the soothing rhetoric of 'transition' with 'translation'. What her work provokes, for this study, is the idea of an alignment between the 'soft skills' - the generic capabilities or attributes at the core of the 'human capital' template - and the disciplinary specificities of cultural and communication studies.

The conclusion that we can draw from our research is that the disciplines encompassed by media, cultural and communication studies deliver capabilities, skills and orientations which are themselves strongly aligned with the kinds of transferable generic attributes which facilitate transition and translation into the workplace. This shows up, we would suggest, in our findings relating to career relevant skills developed during MCCS courses, and special value-adding skills possessed by MCCS graduates. While discipline-specific skills are evident in the skills lists given by graduates (see Tables 4 and 5 for the most common skills mentioned), generic skills such as written communication, verbal communication, critical thinking, and project management skills are more prominent. Generic and specific skills are thoroughly mixed in these answers. Terry Flew’s (2004: 170) claim that the 'discourse of generic graduate capabilities opens up ... a new space for cultural studies’ is indeed played out in these results.

The question of transferability also is supported by the wide range of destination job titles we recorded. There are 110 different destination job titles across the 403 participants. While there is a clear correlation between 'vocational course: specialist destination job’ and between ‘non-vocational course: embedded destination job’, and vocational course graduates assigned somewhat higher course relevance ratings, on average, than non-vocational course graduates, 
there were no differences between vocational and non-vocational graduates in terms of unemployment or time out of the workforce.

We can make too much, in these discipline fields, of the distinction between vocational and non-vocational courses. Given the high level of volatility in the industries and workplaces into which most media, cultural and communication studies graduates go, no matter how vocational course might be, the relevance of their graduating aptitudes, skills and networks will be under pressure, and the thorough mixing of disciplinary and generic attributes and skills we have found in this study may situate them well.

Another broad implication has to do with what we earlier referred to as a more sophisticated account of public good, which may contribute to understanding distinctive ways in which media, cultural and communications graduates contribute to the public good - that the relationship between public and private good is not zero-sum but positive sum. A high proportion, comparatively speaking - nearly one-third - of the QUT cohort were in public service/public sector employment, where pay rates are lower but public good outcomes are, in principle, higher. In the private sector, many graduates from MCCS are in the business of public sphere communication, using attitudes and aptitudes derived, with self-reported high correlation, from the courses they have taken. While the public good embodied in public sphere communication as we see it in journalism, the press, broadcasting, public relations, marketing and advertising, and aspects of social media may have been muted and marginalised in recent decades, it is being dramatically reasserted, for example, in the wake of News International's phone hacking scandals, with Guardian editor-in-chief Alan Rusbridger referring to the press as a 'public good' in a recent oration 
(http://www.guardian.co.uk/media/video/2011/nov/11/alan-rusbridger-orwell-lecture-2011video).

\section{Note}

We would like to thank John Sinclair, chair of the Cultural and Communication Studies section of the Australian Academy of the Humanities, for the opportunity to develop this research for a presentation on 'Graduate Destinations in Cultural and Communication Studies’ at the Academy symposium, 18 November 2011.

\section{References}

Australian Bureau of Statistics 2006, 1220.0 - ANZSCO - Australian and New Zealand Standard Classification of Occupations, First Edition, Revision 1, Available http://www.abs.gov.au/ausstats/abs@.nsf/mf/1220.0 [accessed 5 December 2011].

Coates, H. \& Edwards, D. 2009. The 2008 graduate pathways survey: graduates education and employment outcomes five years after completion of a bachelor degree at an Australian university. Australian Council for Educational Research. Available: http://www.acer.edu.au/research/projects/graduate-pathways-survey-gps/ [Accessed 5 December, 2011].

Cope, Bill and Kalantzis, Mary 2003, Productive Diversity: Organisational Life in the Era of Civic Pluralism and Total Globalisation, Annandale, New South Wales: Pluto Press Australia.

Cultural Studies Review, special issue on ‘Disciplining Innovations’ 17, 2, 2011. 
Cunningham, Stuart (2011) 'Developments in measuring the “creative” workforce.' Cultural Trends, 20(1), pp. 25-40.

DEEWR, 2011, Undergraduate Applications, Offers and Acceptances 2010, Available http://www.deewr.gov.au/HigherEducation/Publications/HEReports/Documents/UndergradA ppsOffersAccept2010.pdf [Accessed 29 November 2011].

Dillman, D. A., Phelps, G., Tortora, R., Swift, K., Kohrell, J., and Berck, J. 2009, Response rate and measurement differences in mixed-mode surveys using mail, telephone, interactive voice response (IVR) and the Internet. Social Science Research, 38(1), pp.1-18.

Flew, Terry 2004, ‘Creativity, the ‘New Humanism’ and Cultural Studies’, Continuum, vol. 18, no. 2, 2004, p. 170.

Freebairn, John 2011, 'Public Funding of Teaching in the Humanities and Social Sciences: An economics perspective', presentation to National seminar on the public funding of teaching in the humanities and social sciences 30 June, Melbourne.

Gannaway, Deanne and Faith Trent, 2008, Nature and Roles of Arts Degrees in Contemporary Society: A national scoping project of Arts programs across Australia, Deans of Arts, Social Sciences and Humanities, Project Final Report, August, http://www.dassh.edu.au/resources/uploads/public/basp/BASP_FinalReport.pdf

Graduate Careers Council of Australia, 2010, Gradfiles: A Snapshot of Employment Outcomes of Recent Higher Education Graduates, Graduate Careers Australia, Available http://start.graduatecareers.com.au/ucm/groups/content/documents/document/gca001800.pdf [accessed 5 December 2011]. 
Hollier, Nathan 2011, 'Let's invest in developing our culture’, The Australian High

Education, 7 September, p 31.

King, Max 2011, ' Research skills development and training for early career researchers and PhD students', presentation to Towards Research Excellence Summit, Informa Higher Education Series, 3 August, Sydney.

Mansfield, Nick 2011, ‘Teaching Illiteracy’, Cultural Studies Review 17, 2, pp.

Matthews, Nicole 2011, ‘Transition or Translation?: Thinking Through Media and Cultural Studies Students’ Experiences after Graduation’ Cultural Studies Review 17, 2, pp.

Norton, Andrew 2011, presentation to National seminar on the public funding of teaching in the humanities and social sciences 30 June, Melbourne.

Rey, Rebecca and Golnar Nabizadeh 2011, 'Going Places: Praxis and Pedagogy in Australian Cultural Studies', Cultural Studies Review 17, 2, pp.

Romer, Paul M. 1994, ‘The Origins of Endogenous Growth’, The Journal of Economic Perspectives, Vol. 8, No. 1. (Winter), pp. 3-22.

Western, Mark, Boreham, Paul, Kubler, Matthias, Laffan, Warren, Western, John, Lawson, Alan and Clague, Denise (2007) PhD graduates 5 to 7 Years out: Employment outcomes, job attributes and the quality of research training: Final Report (Revised) Brisbane: The University of Queensland Social Research Centre (UQSRC), October http://espace.library.uq.edu.au/view/UQ:177864 (for a summary, see http://info.anu.edu.au/ovc/assets/Committees/040PP_Education/uecmtg4_2008/797summaryr esultsgrad.pdf) 
Withers, Glenn 2011, 'Formulating research policy for the university’, presentation to Towards Research Excellence Summit, Informa Higher Education Series, 3 August, Sydney

Word length: under 5500 (excludes cover page and abstract) 